\title{
Intrauterine Growth Restriction (IUGR): Etiology and Diagnosis
}

\author{
Anju Suhag • Vincenzo Berghella
}

Published online: 23 March 2013

(C) Springer Science+Business Media New York 2013

\begin{abstract}
Intrauterine growth restriction (IUGR) is associated with perinatal morbidity and mortality. IUGR is defined as fetus that fails to achieve his growth potential. Antenatal small for gestational age (SGA) is defined as fetus with weight $<10$ th percentile. IUGR and SGA are commonly used interchangeably. The identification of IUGR is important. IUGR identification begins with assessment of risk factor(s), and the diagnosis is made by ultrasound using biometry when this confirms an estimated fetal weight (EFW) of $<10$ th percentile. The common risk factors include maternal causes (hypertension, diabetes, cardiopulmonary disease, anemia, malnutrition, smoking, drug use), fetal causes (genetic disease including aneuploidy, congenital malformations, fetal infection, multiple pregnancies), and placental causes (placental insufficiency, placental infarction, placental mosaicism). Intrauterine growth determines the perinatal, postnatal, and adult life development. IUGR is associated with increased risk of development in adult life of metabolic diseases including but not limited to hypertension, diabetes, obesity, dyslipidemia, and the metabolic syndrome.
\end{abstract}

Keywords Intrauterine growth restriction $\cdot$ Fetal growth restriction $\cdot$ Small for gestational age $\cdot$ Estimated fetal weight $\cdot$ Doppler $\cdot$ Fetal growth

\footnotetext{
A. Suhag $\cdot$ V. Berghella $(\bowtie)$

Department of Obstetrics and Gynecology, Thomas Jefferson

University Hospital, 834 Chestnut Street, Suite 400,

Philadelphia, PA 19107, USA

e-mail: vincenzo.berghella@jefferson.edu

A. Suhag

e-mail: anju.suhag@gmail.com
}

\section{Introduction}

Intrauterine growth restriction (IUGR) is a common and complex obstetric problem. IUGR is noted to affect approximately $10-15 \%$ of pregnant women [1]. IUGR is a diagnosis commonly made antenatally; however, some of these fetuses, especially if unscreened during pregnancy, may be detected only in the newborn period. It is very important for obstetricians and perinatologists to recognize growthrestricted fetuses, because this fetal condition is associated with significant perinatal morbidity and mortality.

Several definitions and terminology has been used in the literature to define IUGR, including but not limited to estimated fetal weight $<25 \%,<15 \%,<10 \%,<5 \%,<3 \%$, $<2.5 \%$, and $<1 \%$ for gestational age [1-3]. Other definitions of IUGR include estimated weight less than 2 standard deviations below the mean weight, abdominal circumference $<10 \%$ for gestational age. Both ACOG and RCOG have adopted the definition of IUGR as estimated fetal weight is less than 10 th percentile $[1,2]$.

The term IUGR has been used interchangeably with small for gestational age (SGA). SGA is a term commonly used for the neonate with birth weight $<10 \%$ [1]. SGA complicated $4-8 \%$ of pregnancies in developed countries and up to $25 \%$ of pregnancies in the developing countries $[4 \bullet \bullet, 5,6]$. In this chapter, we'll use the terms IUGR and "antenatal SGA" interchangeably. The screening and diagnosis of IUGR or antenatal SGA involve accurate dating with an early ultrasound, preferably in the first trimester. Despite best dating estimate, prenatal detection and classification of IUGR and antenatal SGA is still poor. A study by Ott reported that $30 \%$ of neonates with birth weight $<10$ th percentile have IUGR and pathologic SGA, and remainder of the fetuses are normally grown for their potential and are at no increased risk of complications [7]. Clausson et al. in 2001 reported usage of customized growth charts to identify 
one third more antenatal SGA cases compared with those identified using the conventional population based birth weight percentiles [8]. Umbilical artery Doppler is very useful to differentiate the constitutionally small fetus from the pathologically small fetus $[9,10]$.

\section{Morbidity and Mortality in IUGR}

IUGR can have significant consequences in fetal, neonatal, and adult life. To understand the morbidity associated with IUGR, it is important to understand normal fetal growth and development.

Fetal growth starts early in pregnancy by division of cells resulting in cell hyperplasia, followed by increased in size of cell (cell hypertrophy). Over time, the cell hyperplasia stops and the cellular hypertrophy continues to contribute to the growth of the fetus [11]. Placental growth and development is similar to the fetal sequence of cell hyperplasia and hypertrophy across the three trimesters of pregnancy [12•]. The placental growth follows a sigmoid curve that plateaus mid-gestation. Maternal and vascular adaptations occur to maintain the nutrient delivery system between the placenta and the fetus. Amino acid and glucose transport accounts for the exponential fetal growth by increasing muscle bulk and longitudinal growth of $1.5 \%$ per day. After 28 weeks gestation, the majority of the fetal fat gain occurs with continued increase in the fat stores up to $16 \%$ in preparation for the extra uterine life [12•]. Any insult occurring in the fetal growth period can result in fetal growth abnormalities. The earlier the insult is, more likely it will affect the cellular hyperplasia stage of the fetal growth, thereby resulting in symmetrical reduction of the organ size and a symmetrical IUGR fetus. In contrast, if the insult happens later in the gestation (after cell hyperplasia stage), the cell size will be affected, therefore resulting in asymmetrical IUGR [13]. The significance of the symmetrical and asymmetrical IUGR classification is unclear. The asymmetrical IUGR fetuses are noted to be at higher risk for major anomalies, low birth weight, perinatal mortality, hypertensive disorders of pregnancy, preterm delivery, cesarean section, and overall poor outcomes, compared to symmetrical IUGR [14]. Umbilical artery Doppler studies and antenatal surveillance are very good predictors of pregnancy outcomes in both types of IUGR $[15,16]$.

Perinatal morbidity and mortality is significantly increased in the presence of birth weight less than 10th percentile. After prematurity, IUGR is the second leading cause of perinatal mortality. IUGR fetuses have approximately a fivefold to tenfold increased risk of dying in utero, with up to $23 \%$ to $65 \%$ of stillbirths $[17,18]$. Approximately half of preterm stillbirths and one fourth of term stillbirths are growth restricted $[4 \bullet \bullet]$. The corrected perinatal mortality in the entire SGA population is 17.8 per 1,000 live births [1]. The perinatal rate is 21.3 per 1,000 live births in unscreened/undetected SGA versus 8.4 in screened/detected SGA [1]. Therefore, it is important to recognize these fetuses, start early antenatal monitoring and institute timely obstetrical interventions to reduce the perinatal deaths. The risk of fetal death in fetus with IUGR can be affected by several factors, including, but not limited to, the etiology of IUGR, gestational age at diagnosis, and umbilical artery Doppler ultrasound evaluation $[1,16]$. A meta-analysis by Alfirevic et al. concluded that the use of Doppler ultrasound in high-risk pregnancies reduced the risk of perinatal death, induction of labor, and cesarean delivery. The number needed to monitor such fetuses with Doppler ultrasound to prevent one fetal death is 203 with $95 \%$ confidence interval (CI) of 103 to 4,352 [16].

IUGR infants are noted to have increased risk of adverse short- and long-term outcomes compared with SGA children [19]. IUGR increases the risk for intrapartum asphyxia, preterm delivery, and risks associated with preterm delivery, including but not limited to respiratory distress syndrome, intraventricular hemorrhage, and necrotizing enterocolitis $[19,20]$. These infants also are found to have an increase incidence of low Apgar scores, umbilical cord $\mathrm{pH}$ less than 7.0, need for intubation, seizures, sepsis, and neonatal death $[19,21]$. Other neonatal morbidities include polycythemia, hyperbilirubinemia, hypoglycemia, and hypothermia.

Effects of IUGR often affect childhood and adult life, as well. During the childhood period, associations are noted for increased risk of cerebral palsy, growth delay, short stature, and neurodevelopmental impairment [19, 22]. Angelica et al. described the phenomenon of perinatal programming, which refers to the negative effect of the intrauterine or perinatal events on the organ development of the fetus with the possibility of increased susceptibility of the disease in the adulthood [23]. In adult life, individuals who had IUGR were noted to have higher incidence of hypertension, diabetes, obesity, coronary artery disease, stroke, and metabolic syndrome [24].

\section{Etiology}

The causes of IUGR are broadly described under three main categories: maternal, fetal, and placental [25].

\section{Maternal Factors}

Several maternal demographic factors have been associated with IUGR. Women at extremes of reproductive age, especially young maternal age, are at increased risk for IUGR [26-28]. Similarly advanced maternal age has been associated 
with low birth weight [26, 27]. The study by Strobino et al. did not find an association between maternal age and low birth weight and reported an independent effect of social factors, such as ethnicity, poverty status, age at menarche, maternal height, net maternal weight gain, and smoking during pregnancy, on birth weight in adolescent mothers [28].

Maternal race, lower socioeconomic status, and living in a developing country have been found to risk factors for IUGR [29]. Women with lower socioeconomic status and those living in developing countries commonly have poor nutritional status, maternal anemia, and poor prenatal care and substance abuse problem, which affect fetal growth. Maternal weight at birth, low pre-pregnancy weight, and poor weight gain during pregnancy are positively associated with increase in IUGR $[29,30]$. It is unclear if the generalized caloric intake or specific nutrient deficiencies (e.g., glucose, zinc, folate) result in IUGR [15]. The data from the Siege of Leningrad during World War II [31] and the Dutch famine [32] reported maternal intake must be reduced to below 1,500 kilocalories per day before a measurable effect on birth weight becomes evident.

Several environmental and behavioral risk factors are known to cause IUGR. Women residing in high altitude areas are exposed to chronic hypoxia, which results in low birth weight. The studies conducted in Colorado, Peru, and Tibet showed direct relationship of high altitude and low birth weight [33-35]. Smoking in pregnancy is associated is 3.5 -fold increased risk of SGA compared with nonsmokers. Up to $19 \%$ of term low birth weight (LBW) has been attributed to smoking during pregnancy. Smoking is noted to have dose-, duration-, and trimesterrelated effect on fetal growth. Heavy smoking ( $>15$ cigarette daily) and smoking throughout the pregnancy, especially in third trimester, is associated with low birth weight $[36,37]$. Smoking cessation in pregnancy can prevent $17 \%$ of LBW births. Women are more likely to quit during the pregnancy, therefore, pregnant women should be strongly encouraged to stop smoking, at any time in pregnancy, and as early as possible. A study by MacArthur et al. showed that birth weight of infants born to women who quit smoking before 16 weeks of gestation was similar to that of babies born to women who never smoked [38]. The safe amount of alcohol during pregnancy is unknown. The effect on fetal growth is related to the amount and gestational age of consumption of alcohol [37]. Fetal alcohol syndrome is commonly associated with IUGR. Maternal illicit drug use has been associated with an increasing incidence of SGA infants in mothers with heroin [39] and cocaine addiction [40], with rates as high as $50 \%$ and $30 \%$, respectively. Exposure to various medications, such as warfarin, anticonvulsants, antineoplastic agents, and folic acidantagonists (such as trimethoprim-sulfamethoxazole, phenobarbital), can result in IUGR [41].
A short interpregnancy interval is associated with IUGR [42]. Artificial reproductive techniques (ART) and infertility are independent risk factors of IUGR. There is some evidence that superovulation can affect DNA methylation, causing imprinting changes, which can affect fetal growth and development. Singleton infants resulting from in vitro fertilization (IVF) and superovulation without ART are at higher risk for LBW and SGA compared with no treatment; however, no such association is found in multiple pregnancies [43].

Several other maternal disease conditions are associated with IUGR. These maternal causes of IUGR commonly are related to reduced uteroplacental blood flow, reduced oxygen-carrying capacity, or decreased nutrition to the fetus [25]. Maternal systemic conditions, such as chronic hypertension, preeclampsia, pregestational diabetes (class C, D, R, F), chronic renal insufficiency, systemic lupus erythematosus (SLE), antiphospholipid syndrome (APS), can affect the fetal microcirculation and thereby decrease fetal perfusion, leading to hypoxia and IUGR [41]. The uteroplacental insufficiency associated with preeclampsia can be caused by failure of trophoblast invasion of the myometrial segment of spiral arteries, leading to failure of dilatation of these vessels, atherosis, occlusion, and infarction [44]. Diabetes can cause hyperglycemia-related damage to the endothelial lining of micro- and macrovascular system and structural changes in placental decidual arteries, therefore causing hypoperfusion and growth restriction in fetuses of diabetic women [45]. Renal diseases (nephrotic syndrome, chronic renal failure, renal transplant, hemodialysis), autoimmune diseases (SLE), and acquired thrombophilias [APS especially anticardiolipin antibodies (ACA)] have been associated with IUGR [4••]. In contrast, inherited thrombophilias are not associated with IUGR. Chronic maternal hypoxemia due to pulmonary disease (uncontrolled asthma, COPD, cystic fibrosis), cardiac disease (cyanotic congenital heart disease, heart failure, poor functional status with New York Heart Association class III/IV), or hematologic disorders (severe anemia, sickle cell anemia, b-thalassemia, hemoglobin $\mathrm{H}$ disease) is associated with diminished fetal growth $[1,4 \bullet \bullet, 12 \bullet]$. Maternal malnutrition and gastrointestinal conditions (such as Crohn's disease, ulcerative colitis, and gastrointestinal bypass surgery) can cause lower birth weight because of decreased nutrition to the fetus. Protein deficiency or restrictions can be associated with symmetrical IUGR.

Other maternal causes include uterine factor (e.g., fibroid, müllerian anomalies) [46, 47], maternal periodontal disease [48], and genetic conditions, such as angiotensinogen gene mutations. Prior history of SGA infant increases the risk of recurrent SGA to up to $25 \%$. The women who were SGA at birth have twofold increase for risk of fetal growth restriction in their offspring [49]. 


\section{Fetal Factors}

Fetal factors can vary from genetic causes, congenital malformations, fetal infection, or other causes, including multiple pregnancies.

Genetic causes can contribute to 5-20\% of IUGR, especially for early onset growth restricted fetuses. Genetic causes further include various abnormalities, such as chromosomal abnormalities, e.g., trisomy $21,18,13$, and 16 $[12 \cdot, 25]$. Of these, trisomy 18 is associated with more severe IUGR compared with trisomy 21 or 13 . Trisomy 16 is known to be a lethal chromosomal abnormality in the nonmosaic state; however, in the presence of placenta mosaicism, trisomy 16 can result in IUGR. Autosomal abnormalities, including deletion of chromosomes 4 (WolfHirschhorn syndrome), 5 (Cri du chat syndrome), 13, 18, and ring chromosome structural alterations, have all been associated with IUGR $[25,50]$. Other chromosomal abnormalities linked to IUGR include uniparental disomy of chromosome 6,14, and 16. Abnormalities of sex chromosomes, including complete deletion of $\mathrm{X}$ chromosome resulting in Turner's syndrome (45XO), extra or missing sex chromosomes also have been associated with IUGR. Single gene disorders, such as Cornelia de Lange syndrome, Russell Silver syndrome, Fanconi's anemia, Bloom syndrome and some skeletal dysplasias, have been associated with IUGR. Other genetic factors include gene polymorphisms of the matrix metalloproteinase $2 \mathrm{C}-1306 \mathrm{~T}$ gene in the fetal and maternal LRP8 gene, maternal detoxification enzyme CYPP1A1 gene, as well as and mutations in the gene for insulin-like growth factor [25, 41].

Congenital malformations, including congenital heart disease, diaphragmatic hernia, abdominal wall defects (omphalocele, gastroschisis), renal agenesis or dysplasia, anencephaly, and single umbilical artery, are associated with IUGR [50, 51].

Infections accounts for less than $5 \%$ of IUGR fetuses. Common infections include viral (rubella, CMV, herpes, varicella, herpes zoster, HIV) and parasitic infections (toxoplasmosis, syphilis, malaria). Bacterial infections are a less likely etiology of IUGR; however, chlamydia, mycoplasma, listeria, and tuberculosis have been reported to cause fetal growth restriction $[25,41]$. The most common infectious etiology of IUGR in developed countries is CMV. The mechanism of the impairment of fetal growth in CMV results from direct cytolysis and loss of cell function in various organ system in the fetus [52]. In developing countries, especially the sub-Saharan Africa, IUGR commonly results from Malaria in pregnancy [53]. Malaria infection in the pregnancy results in low birth weight and IUGR secondary to poor oxygen and nutrient transfer to the fetus from the destruction of red blood cells and placental malaria, which results from plasmodium infected RBC causing vascular obstruction. Other viral, parasitic, and bacterial infections are associated with direct cell damage, or transplacental passage causing fetal infection, or placental vascular insufficiency.

Multiple pregnancies are known to have fetal growth restriction as one of the common complications, and account for up to $3 \%$ of all cases of IUGR. Multiple pregnancies are at fivefold to tenfold higher risk of IUGR compared with singleton pregnancies with $15-30 \%$ incidence of fetal growth restriction in twins [54]. The risk of fetal growth restriction depends on a variety of factors, including number of fetuses, chorionicity, presence of congenital anomaly or umbilical cord abnormalities, such as velamentous cord insertion or two-vessel cord, unequal placenta sharing with selective IUGR, presence of twintwin transfusion syndrome, conjoint twin, acardia, and maternal under nutrition $[55,56 \bullet]$. Multiple pregnancies have a growth rate similar to singleton pregnancy until 3032 weeks [57], after which the growth velocities of abdominal circumference, femur length, and biparietal diameter are noted to decrease. Growth discordance of $15-25 \%$ or higher is associated with increased risk of neonatal morbidity and mortality $\left[1,56^{\circ}\right]$.

\section{Placental Factors}

Placental insufficiency accounts for many cases of IUGR and can affect up to $3 \%$ or more of all pregnancies. The pathogenesis of IUGR is not well defined; defects in the placental circulation and transport can affect the nutrient transport to the fetus, resulting in IUGR. The relative decrease in placental mass and function can result in the development of IUGR [12•]. Several animal models have shown that fetal growth can be impaired when up to $50 \%$ of the placental mass is removed. Like the animal model, growth-restricted human fetuses are noted to have approximately a $24 \%$ smaller placental weight compared with a normally grown fetus. In addition to placental mass and function, immunological disturbances at the maternal-fetal interface may result in IUGR. The activation of dendritic cells (DCs) at the maternal-fetal interface contributes to the optimal immune response at level of decidua to support fetal-placental development. These DCs can be easily accessed in the peripheral blood and their activation status can be determined in a normal pregnancy. A recent study by Cappelletti et al. noted reduced number of circulating DCs, lacking activation in pregnancy complicated by IUGR, compared with normal healthy pregnancy. These changes in DCs if confirmed at maternal-fetal interface can potentially impact the vascular development in decidua and fetal growth during pregnancy [58].

Abnormal implantation, such as placenta previa, can result in suboptimal nutrition to the fetus. Other common 
placental causes of IUGR include placental abruption, placenta accreta, placental infarction, fetal villous obliteration, circumvallate placenta, and placental hemangioma $[25,59]$. Confined placental mosaicism, single umbilical artery, and velamentous cord insertion also can result in growth restriction [41,60]. Rare placental tumor, such as chorioangioma, can decrease the uteroplacental flow, which can impair fetal growth. Diffuse chronic villitis of unknown etiology can be associated with IUGR. A recent study by Sato et al. noted higher prevalence of placental infarction, fetal vessel thrombosis, and chronic villitis in IUGR fetuses compared with normal growth pregnancies [61].

\section{Diagnosis}

IUGR (also called here antenatal SGA) is diagnosed based on establishment of accurate early dating, assessment of risk factors, followed by ultrasound for fetal growth. There are additional tests involved to rule out any other underlying cause. The diagnosis of IUGR (aka antenatal SGA) is made when the EFW is $<10 \%$ percentile for gestational age as calculated by biometric measurements (Fig. 1).

The first step in diagnosis of fetus with growth restriction is to establish accurate dating. The algorithm for determining the estimated date of delivery is as follows: before 13 6/7 weeks gestation, if LMP and ultrasound based dating differed by 7 days, preference is given to the ultrasoundbased date; between 14 and 19 6/7 weeks gestation, if LMP and ultrasound-based dating differed by 10 days, preference is given to the ultrasound-based date [62].

After establishment of accurate dating, identification of risk factors by obtaining medical history is critical to identify IUGR (Table 1). A detailed medical history can be useful to identify maternal systemic disease, which can affect fetal growth. Poorly controlled maternal diseases, such as hypertension, renal disease, long-standing pregestational diabetes with vasculopathy, and other systemic disease, can impact fetal growth significantly. Identification of the modifiable risk factors, such as smoking and illicit drug use, can be useful in providing preventive interventions. Monitoring of weight gain on prenatal visit can identify the maternal nutrition. Also, measurement of the symphysis-fundal height (SFH) height provides a helpful measure to assess fetal growth during office visits.

Based on history and risk-based assessment, infectious workup, including serology for maternal $\operatorname{IgG}$ and $\operatorname{IgM}$ for CMV, toxoplasmosis, and HSV may be considered. Rubella immunity also should be tested if not performed with the routine prenatal labs. There is insufficient evidence to test routinely for thrombophilia; however, APS testing (ACA IgG and $\operatorname{IgM}$, lupus anticoagulant, beta- 2 microglobulin IgG and $\operatorname{IgM}$ ) could be performed to manage the current and future pregnancy [63].

There are various screening techniques that would further warrant the growth ultrasound for the diagnosis of IUGR. Common screening methods include serum analytes screening, uterine artery Doppler, and SFH. Abnormal first and second

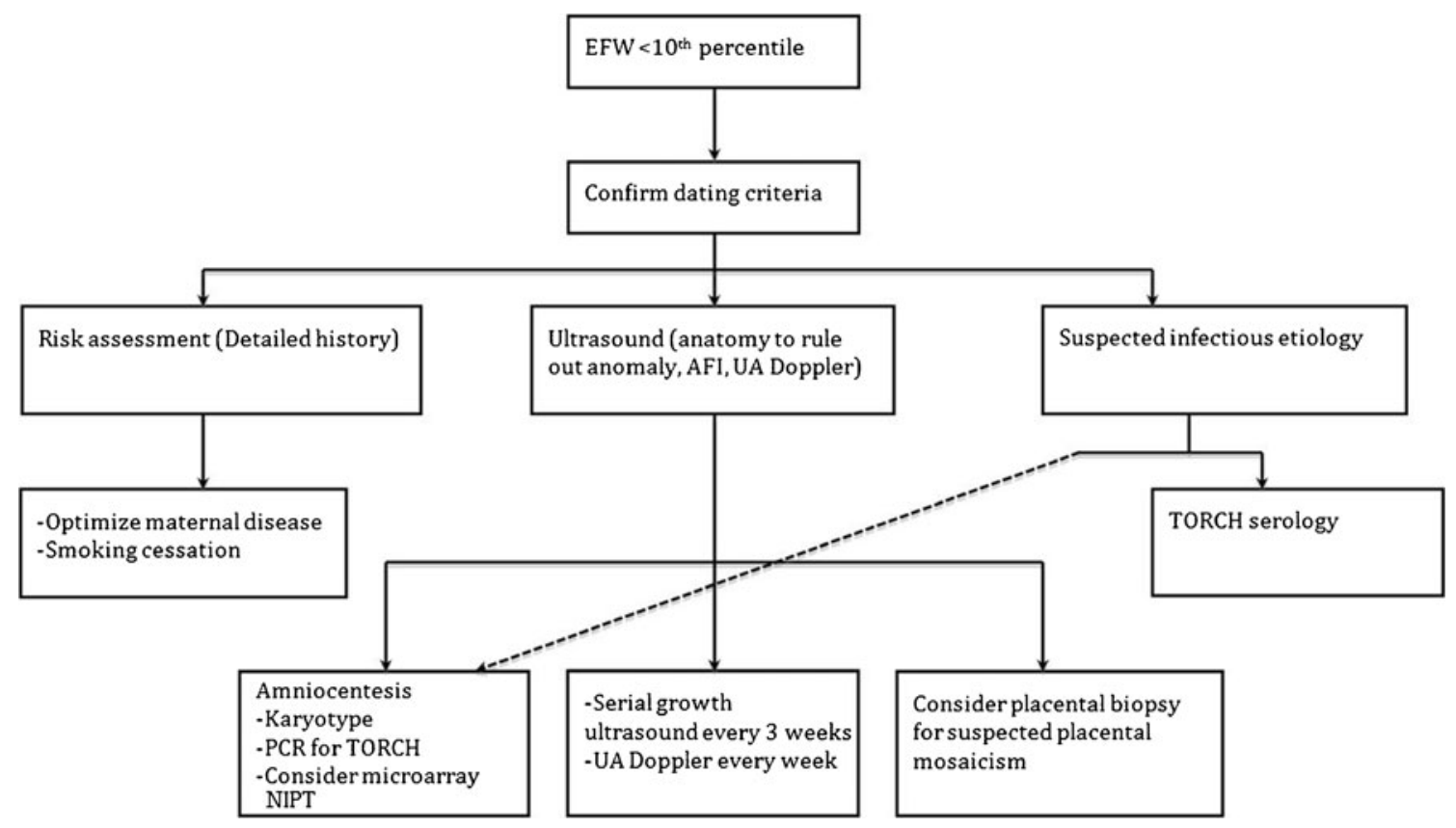

Fig. $1 \mathrm{EFW}=$ estimated fetal weight; $\mathrm{UA}=$ umbilical artery; $\mathrm{AFI}=$ amniotic fluid index; TORCH=toxoplasmosis, other (syphilis), rubella, cytomegalovirus, herpes; $\mathrm{PCR}=$ polymerase chain reaction; $\mathrm{NIPT}=$ non-invasive prenatal testing 
Table 1 Etiology of IUGR

\begin{tabular}{|c|c|c|}
\hline Maternal factors & Fetal factors & Placental factors \\
\hline Demographics: & Genetic: & Placenta: \\
\hline Extreme of maternal age & Trisomy $21,18,13$ & Placental abruption \\
\hline Race & Turners syndrome & Placenta accreta \\
\hline Low pre-pregnancy weight & Deletion of chromosome 4,5 & Placental infarction \\
\hline Poor maternal weight gain & Genetic syndromes & Circumvallate placenta \\
\hline Obstetrical: & Congenital malformations: & Confined placental mosaicism \\
\hline Short inter-pregnancy interval & Congenital heart disease & Placental hemangioma \\
\hline Prior history of small for gestational age (SGA) & $\mathrm{CDH}$ & Placental chorangioma \\
\hline Behavioral/environmental: & Abdominal wall defect & Diffuse chronic villitis \\
\hline Smoking & Anencephaly & Fetal villous obliteration \\
\hline Alcohol & Infection: & Umbilical cord: \\
\hline Drug use & TORCH & Velamentous cord insertion \\
\hline High altitude & Malaria & Single umbilical artery \\
\hline Systemic disease: & Others: Chlamydia, Mycoplasma, Listeria, TB & \\
\hline Hypertension (chronic hypertension, preeclampsia) & Multiple pregnancy & \\
\hline \multicolumn{3}{|l|}{ Pregestational Diabetes } \\
\hline \multicolumn{3}{|l|}{ Renal disease } \\
\hline \multicolumn{3}{|l|}{ Anemia } \\
\hline \multicolumn{3}{|l|}{ Pulmonary disease } \\
\hline \multicolumn{3}{|l|}{ Congenital heart disease } \\
\hline \multicolumn{3}{|l|}{ Autoimmune disease } \\
\hline \multicolumn{3}{|l|}{ Antiphospholipid syndrome } \\
\hline \multicolumn{3}{|c|}{$\begin{array}{l}\text { GI disease (Crohn's disease, ulcerative colitis, gastric bypass, } \\
\text { malabsorption) }\end{array}$} \\
\hline \multicolumn{3}{|l|}{ Malnutrition } \\
\hline \multicolumn{3}{|l|}{ Transplant recipient (Renal) } \\
\hline \multicolumn{3}{|l|}{ Others: } \\
\hline \multicolumn{3}{|l|}{ Artificial reproductive technologies (ART) } \\
\hline \multicolumn{3}{|l|}{ Uterine factors (fibroid, müllerian anomalies) } \\
\hline \multicolumn{3}{|l|}{ Medications (anticonvulsants, beta blockers) } \\
\hline Angiotensin gene mutation & & \\
\hline
\end{tabular}

trimester serum screening can be associated with IUGR and abnormal pregnancy outcomes. In first trimester, unexplained low pregnancy-associated plasma protein A (PAPP-A) or human chorionic gonadotropin (hCG) [64], and the unexplained elevation in serum AFP, HCG, or inhibin A, or low estriol in second trimester, could be associated birth weight $<10$ th percentile $[65,66]$. The second screening tool used in the first trimester includes uterine artery Doppler. Abnormal first trimester uterine artery Doppler is associated with IUGR. The sensitivity of the association of the uterine artery Doppler with abnormal pulsatility index (PI) with IUGR is $12 \%$ in the first trimester [67]. Uterine artery Doppler seems to be a poor screening tool; however, this information can be used to start the preventive therapy with baby aspirin before 16 weeks gestation in women at high risk for IUGR
[68•]. Another simple tool commonly used in office includes measurement of SFH (which is done along the fetal axis from fundus to pubic symphysis), which could be followed serially during the prenatal visits [69]. The definition of normal SFH is fundal height \pm 2 or $\pm 3 \mathrm{~cm}$ of gestational age. SFH measurement can be associated with interobserver variability and low accuracy. Compared with clinical assessment by abdominal palpation, SFH on customized growth charts increase in antenatal detection of SGA babies from $29 \%$ to $54 \%$ with low false-positive rate [70]

Suspected growth restriction could be further evaluated by detailed ultrasound of fetus to identify fetal anomalies in addition to biometry. In high-risk pregnancies, serial growth ultrasound or abdominal circumference (AC) measurements are the best predictors of fetal growth [71, 72]. Ultrasound has been used for calculation of the estimated fetal weight 
for years. The four basic measurements, including biparietal diameter (BPD), head circumference (HC), femur length (FL), and abdominal circumference (AC), can be performed starting at 14 weeks gestation using standard AIUM guidelines [73]. The calculation of estimated fetal weight (EFW) was done in the past using several formulas, of which Hadlock $\mathrm{C}$ is the most common formula used in clinical practice [74•].

The accuracy and reproducibility of various biometry measurements are described in the literature. After 14 weeks, BPD is noted to be highly reproducible parameter; however, the shape of head can affect BPD measurement. Corrected BPD formulas are available for the measurement of abnormally shaped head. The variability of the measurements of $\mathrm{BPD}, \mathrm{HC}$, and FL is less compared with AC between 1420 weeks. However, the variability is noted to increase with increasing gestational age and size from 20-42 weeks gestation [75]. The inter- and intraobserver variability could be affected by various factors. The common factors include fetal presentation (head low in the pelvis), fetal activity (breathing movement), amount of amniotic fluid, type of fetal measurement (linear versus ellipse), the plane of measurement, the placement of caliper, gestational age, and maternal body habitus [76]. Zalud et al. found the measurements produced by the automated OB software to be comparable with the sonographer's measurement, with lesser errors noted on automated measurements. The results of automated OB software program appears to be a great future tool in fetal biometry; however, the standard biometry practice defined by AIUM is used until there is more evidence to automated biometry [77].

There are other ultrasound parameters, such as AC alone, $\mathrm{HC} / \mathrm{AC}$ ratio, FL/AC ratio, and ponderal index (PI), which can be used in identifying IUGR fetuses. AC alone can be a single sensitive parameter for detecting IUGR, with sensitivity, specificity, positive, and negative predictive values of $\mathrm{AC}$ in predicting SGA is $61 \%, 95 \%, 86 \%$, and $83 \%$. The $\mathrm{HC} / \mathrm{AC}$ ratio and FL/AC ratio can predict accurately the asymmetric IUGR related to placental insufficiency, therefore, can be used as screening parameter for high-risk pregnancies where IUGR is suspected [78, 79]. The fetal PI is calculated using sonographically derived EFW and FL measurement. This index is more useful to diagnose IUGR in the newborn. However, the correlations of the fetal PI and neonatal PI is poor; therefore, PI is of limited utility during the pregnancy [80]. Another parameter used is transcerebellar diameter (TCD), which is not affected by IUGR and therefore can be used as an independent indicator of GA [81]. The $\mathrm{TCD} / \mathrm{AC}$ ratio has been shown to predict IUGR if the ratio is more than 2 SD above the mean; however, this ratio is not routinely used until proven by further studies [82].

The physiological variables, including maternal height, weight, parity, ethnicity, fetal sex, and gestational age, are known to affect fetal growth; therefore, several adjusted and customized growth chart and models are available [83, 84]. The coefficient of such growth charts have been assessed in the U.S. population; however, the practice of such growth charts in the ethnically heterogeneous and geographically mobile U.S. population is yet to be determined $[1,85]$.

The umbilical artery (UA) Doppler ultrasound in the second trimester in high-risk pregnancies could be used to predict the development of the IUGR later in the pregnancy [16]. However, the utility of routine UA Doppler's in screening of IUGR in low risk population is not proven. UA Doppler can be used in the management and follow-up of the fetuses with IUGR. The pattern of changes in the UA Doppler velocimetry can further predict the fetal outcome. Progressive decrease in the diastolic flow in UA Doppler reflects the increasing placental resistance from the obliteration of the placental tertiary stem villi, and the reversal in UA Doppler can be seen after $70 \%$ of placental tertiary villi are obstructed [86]. Progressive hypoxemia can result in redistribution of the blood flow centrally to brain, heart, and adrenals. This results in the increase in diastolic flow in the middle cerebral artery (MCA). In the advanced stages of IUGR, the central venous circulation of the fetus is affected [87, 88]. The Doppler waveform from ductus venosus (DV) can reflect the end-diastolic pressure in the right ventricle from the increased right ventricular afterload [89]. Abnormal DV waveforms (decreased, absent, or reversed) can predict the fetal acidemia and increased risk of perinatal death [90].

The invasive techniques, including amniocentesis and central villus sampling (CVS), are available for identifying the causes of IUGR. Once the diagnosis is established with the ultrasound before 24 weeks gestation and cause of the IUGR is unknown, amniocentesis should be offered for the karyotype and infectious workup (PCR for toxoplasmosis, CMV, HSV). If placental cause is suspected, the placental biopsy may be considered to evaluate for placental mosaicism [60].

\section{Conclusions}

IUGR is associated with high perinatal morbidity and mortality. It is important for obstetricians and perinatologist to recognize the fetus(es) at risk of IUGR. The foremost priority is to establish the dating criteria and further identify the modifiable risk factors and optimize the maternal systemic disease. The women at risk for IUGR can be assessed with uterine artery Doppler to further evaluate the initiation of baby ASA before 16 weeks gestation. Diagnosis of IUGR is made by when the ultrasound EFW is less than 10th percentile. The umbilical artery Doppler should be performed in IUGR fetuses to formulate the antenatal management plans. 
Invasive testing should be offered to rule out aneuploidy and in utero fetal infection. Serial growth ultrasound and UA Doppler studies are used to follow-up the fetus(es) with IUGR.

Conflict of Interest Vincenzo Berghella declares that he has no conflict of interest.

Anju Suhag declares that she has no conflict of interest.

\section{References}

Papers of particular interest, published recently, have been highlighted as:

- Of importance

-• Of major importance

1. American College of Obstetricians and Gynecologists. Intrauterine growth restriction. Practice Bulletin no. 12, 2000, Washington DC. http://www.acog.org. Accessed 25 Dec 2012.

2. Royal College of Obstetricians and Gynaecologists.http:// www.rcog.org.uk/womens-health/investigation-and-managementsmall-gestational-age-fetus-green-top-31. Published November 1, 2002. Accessed 25 Dec 2012.

3. Chauhan SP, Magann EF. Screening for fetal growth restriction. Clin Obstet Gynecol. 2006;49:284-94.

4. •- Reeves S, Galan HL. Fetal growth restriction. In: Berghella $\mathrm{V}$, editor. Maternal-fetal evidence based guidelines. 2nd ed. London: Informa Health Care; 2012. p. 329-44. Excellent evidence-based chapter on IUGR, easy to read format with tables and algorithms.

5. Gardosi J. Clinical strategies for improving the detection of fetal growth restriction. Clin Perinatol. 2011;38:21-31.

6. De Onis M, Blossner M, Villar J. Levels and patterns of intrauterine growth retardation in developing countries. Eur J Clin Nutr. 1998;52(Supp 1):S5-S15.

7. Ott WJ. The diagnosis of altered fetal growth. Obstet Gynecol Clin North Am. 1988;15:237-63.

8. Clausson B, Gardosi J, Francis A, et al. Perinatal outcome in SGA births defined by customised versus population-based birthweight standards. BJOG. 2001;108:830-4.

9. Gagnon R, Van de Hof M. The use of fetal Doppler in obstetrics. J Obstet Gynecol Can. 2003;25(7):601-7.

10. American College of Obstetricians and Gynecologists. ACOG committee opinion. Utility of antepartum umbilical artery Doppler velocimetry in intrauterine growth restriction. Number188, October 1997 (replaces No 116, November 1992). Committee on Obstetric Practice. Int J Gynaecol Obstet. 1997;59:269-70.

11. Winick M. Fetal malnutrition. Clin Obstet Gynecol. 1970;13 (3):526-41.

12. Baschat AA, Galan HL, Gabbe SG. Intrauterine growth restriction. In: Gabbe SG, Neibyl JR, Simpson JL, editors. Obstetrics normal and problem pregnancies. Philadelphia: Elsevier; 2012. p. 706-41. Excellent in-depth review of pathophysiology, risk factors and evaluation of IUGR.

13. Villar J, Belizan JM. The timing factor in the pathophysiology of the intrauterine growth retardation syndrome. Obstet Gynecol Surv. 1982;37(8):499-506.
14. Dashe J, McIntire D, Lucas M, et al. Effects of symmetrical and asymmetrical fetal growth on pregnancy outcomes. Obstet Gynecol. 2000;1996(3):321-7.

15. David C, Gabriellie S, Pilu G, et al. The head to abdomen circumference ratio: a reappraisal. Ultrasound Obstet Gynecol. 1995;5 (4):256-9.

16. Alfirevic Z, Stampalija T, Gyte GML. Fetal and umbilical Doppler ultrasound in high-risk pregnancies. Cochrane Database Syst Rev. 2010;1:CD007529.

17. Chen HY, Chauhan SP, Ward TC, et al. Aberrant fetal growth and early, late, and postneonatal mortality: an analysis of Milwaukee births, 1996-2007. Am J Obstet Gynecol. 2011;204:261. e1-e261, e10.

18. Gardosi J, Clausson B, Francis A. The value of customised centiles in assessing perinatal mortality risk associated with parity and maternal size. Br J Obstet Gynaecol. 2009;116:1356-63.

19. von Beckerath AK, Kollmann M, Rotky-Fast C, et al. Perinatal complications and long-term neurodevelopmental outcome of infants with intrauterine growth restriction. Am J Obstet Gynecol. 2013;208(2):130.e1-6.

20. Bernstein IM, Horbar JD, et al. Morbidity and mortality among very-low-birth-weight neonates with intrauterine growth restriction. The Vermont Oxford Network. Am J Obstet Gynecol. 2000;182:198-206.

21. McIntire DD, Bloom SL, Casey BM, et al. Birth weight in relation to morbidity and mortality among newborn infants. N Engl J Med. 1999;340:1234-8.

22. Pallotto E, Kilbride H. Perinatal outcomes and later implications of intrauterine growth restriction. Clin Obstet Gynecol. 2006;49 (2):257-69.

23. Angelica D, Giovanni O, Vassilios F. Physiopathology of intrauterine growth retardation: from classic data to metabolomics. J Maternal-Fetal Neonatal Med. 2012;25(S5):13-8.

24. Barker D. Adult consequences of fetal growth restriction. Clin Obstet Gynecol. 2006;49(2):270-83.

25. Hendrix N, Berghella V. Non-placental causes of intrauterine growth restriction. Semin Perinatol. 2008;32(3):161-5.

26. Lee KS, Ferguson RM, Corpuz M, Gartner LM. Maternal age and incidence of low birth weight at term: a population study. Am J Obstet Gynecol. 1988;158(1):84-9.

27. Aldous MB, Edmonson MB. Maternal age at first childbirth and risk of low birth weight and preterm delivery in Washington State. JAMA. 1993;270(21):2574-5.

28. Strobino DM, Ensminger ME, Kim YJ, Nanda J. Mechanisms for maternal age differences in birth weight. Am J Epidemiol. 1995;142(5):504-14.

29. Wen SW, Goldenberg RL, Cutter GR, et al. Intrauterine growth retardation and preterm delivery: prenatal risk factors in an indigent population. Am J Obstet Gynecol. 1990;162:213-8.

30. Berghella V. Prevention of recurrent fetal growth restriction. Obstet Gynecol. 2007;110(4):904-12.

31. Anatov AN. Children born during the siege of Leningrad in 1942. J Pediatr. 1947;30:250-9.

32. Smith CA. Effect of maternal undernutrition upon the newborn infant in Holland (1944-1945). J Pediatr. 1947;30:229-43.

33. Galan HL, Rigano S, Radaelli T, et al. Reduction of subcutaneous mass, but not lean mass, in normal fetuses in Denver, Colorado. Am J Obstet Gynecol. 2001;185:839-44.

34. Mortola JP, Frappell PB, Aguero L, Armstrong K. Birth weight and altitude: a study in Peruvian communities. J Pediatr. 2000;136:324-9.

35. Kametas NA, McAuliffe F, Krampl E, et al. Maternal cardiac function during pregnancy at high altitude. BJOG. 2004;111:1051-8.

36. Lieberman E, Gremy I, Lang JM, Cohen AP. Low birth weight at term and the timing of fetal exposure to maternal smoking. Am J Public Health. 1994;84(7):1127-31. 
37. Shu XO, Hatch MC, Mills J, et al. Maternal smoking, alcohol drinking, caffeine consumption, and fetal growth: results from a prospective study. Epidemiology. 1995;6:115-20.

38. MacArthur C, Knox EG. Smoking in pregnancy: effects of stopping at different stages. Br J Obstet Gynaecol. 1988;95:551-5.

39. Naeye RL, Blanc W, Leblanc W, Khatamee MA. Fetal complications of maternal heroin addiction: abnormal growth, infections and episodes of stress. J Pediatr. 1973;83:1055-61.

40. Fulroth R, Phillips B, Durand DJ. Perinatal outcome of infants exposed to cocaine and/or heroin in utero. Am J Dis Child. 1989;143:905-10.

41. Divon MY, Ferber A. Overview of causes and risk factors for fetal growth restriction In: Lockwood CJ, Barss VA (eds) UpToDate http://www.uptodate.com accessed 12/25/2012.

42. Zhu BP, Rolfs RT, Nangle BE, Horan JM. Effect of the interval between pregnancies on perinatal outcomes. N Engl J Med. 1994;340(8):589-94.

43. - D'Angelo DV, Whitehead N, Helms K, et al. Birth outcomes of intended pregnancies among women who used assisted reproductive technology, ovulation stimulation, or no treatment. Fertil Steril. 2011;96(2):314-320.e2. This population-based study reviews the affect of ART techniques on birth outcomes.

44. Walfisch A, Hallack M. Hypertension. In: James DK, Steer PJ, Weiner CP, Gonik B, editors. High risk pregnancy management options. Philadelphia: Elsevier; 2006. p. 772-97.

45. Ang C, Howe D, Lumsden M. Diabetes. In: James DK, Steer PJ, Weiner CP, Gonik B, editors. High-risk pregnancy management options. Philadelphia: Elsevier; 2006. p. 986-1004.

46. Klatsky PC, Tran ND, Caughey AB, Fujimoto VY. Fibroids and reproductive outcomes: a systematic literature review from conception to delivery. Am J Obstet Gynecol. 2008;198:357-66.

47. Cooney MJ, Benson CB, Doubilet PM. Outcome of pregnancies in women with uterine duplication anomalies. J Clin Ultrasound. 1998;26(1):3-6.

48. Khader YS, Ta'ani Q. Periodontal diseases and the risk of preterm birth and low birth weight: a meta-analysis. J Periodontol. 2005;76 (2):161-5.

49. Klebanoff MA, Meirik O, Berendes HW. Second-generation consequences of small-for-dates birth. Pediatrics. 1989;84(2):343-7.

50. Lin CC, Santolaya-Forgas J. Current concepts of fetal growth restriction: part I. Causes, classification, and pathophysiology. Obstet Gynecol. 1998;92(6):1044-55.

51. Khoury MJ, Erickson JD, Cordero JF, McCarthy BJ. Congenital malformations and intrauterine growth retardation: a population study. Pediatrics. 1988;82(1):83-90.

52. Wendel GD. Cytomegalovirus, genital herpes, rubella, syphilis and toxoplasmosis. In: Queenan JT, Hobbins JC, Spong CY, editors. Protocols for high-risk pregnancies: an evidence-based approach. 5th ed. Oxford: Wiley-Blackwell; 2010. doi:10.1002/ $9781444323870 \cdot \operatorname{ch} 35$

53. Adanu RMK. Malaria in pregnancy. In: Queenan JT, Hobbins JC, Spong CY, editors. Protocols for high-risk pregnancies: an evidence-based approach. 5th ed. Oxford: Wiley-Blackwell; 2010. doi:10.1002/9781444323870.ch37.

54. Divon MY, Weiner Z. Ultrasound in twin pregnancy. Semin Perinatol. 1995;19:404-12.

55. D'Alton ME, Simpson LL. Syndromes in twins. Semin Perinatol. 1995;19:375-86.

56. - Miller J, Chauhan SP, Abuhamad AZ. Discordant twins: diagnosis, evaluation and management. Am J Obstet Gynecol. 2012;206(1):10 20. This expert review will help us in understanding the key aspects of evidence-based management of discordant twins.

57. Guenwald P. Growth of the human fetus II. Abnormal growth in twins and infants of mothers with diabetes, hypertension, or isoimmunization. Am J Obstet Gynecol. 1966;94:1120-32.
58. Cappelletti M, Giannelli S, Martinelli A, et al. Lack of activation of peripheral blood dendritic cells in human pregnancies complicated by intrauterine growth restriction. Placenta. 2013;34(1):35-41.

59. Laurini R, Laurin J, Marsal K. Placental histology and fetal blood flow in intrauterine growth retardation. Acta Obstet Gynecol Scand. 1994;73:529e34.

60. Wilkins-Haug L, Roberts DJ, Morton CC. Confined placental mosaicism and intrauterine growth retardation: a case control analysis of placentas at delivery. Am J Obstet Gynecol. 1995; 172:44e50.

61. Sato Y, Benirschke, Marutsuka K, et al. Associations of intrauterine growth restriction with placental pathological factors, maternal factors and fetal factors; clinicopathological findings of 257 Japanese cases. Histol Histopathol. 2013;28(1):127-32.

62. March MI, Chauhan SP, Abuhamad A. Ultrasound. In: Berghella $\mathrm{V}$, editor. Obstetric evidence-based guidelines. 2nd ed. UK: Informa Healthcare; 2012. p. 41-6.

63. Robertson $\mathrm{L}, \mathrm{Wu} \mathrm{O}$, Langhorne $\mathrm{P}$, et al. Thrombosis: Risk and Economic Assessment of Thrombophilia Screening (TREATS) Study. Thrombophilia in pregnancy: a systemic review. Br J Haematol. 2006;132(2):171-96.

64. Dugoff L, Hobbins JC, Malone FD, et al. First-trimester maternal serum PAPP-A and free-beta subunit human chorionic gonadotropin concentrations and nuchal translucency are associated with obstetric complications: a population-based screening study. Am J Obstet Gynecol. 2004;191:1446-51.

65. Dugoff L, Hobbins JC, Malone FD, et al. FASTER Trial Research Consortium. Obstet Gynecol. 2005;106(2):260-7.

66. Dugoff L. First and second trimester maternal serum markers for aneuploidy and adverse pregnancy outcomes. Obstet Gynecol. 2010;115(5):1052-61.

67. Martin AM, Bindra R, Curcio $P$, et al. Screening for preeclampsia and fetal growth restriction by uterine artery Doppler at 11-14 weeks of gestation. Ultrasound Obstet Gynecol. 2001;18(6):583-6.

68. - Bujold E, Roberge S, Lacasse Y, et al. Prevention of preeclampsia and intrauterine growth restriction with aspirin started in early pregnancy: a meta-analysis. Obstet Gynecol. 2010;116(2 Pt 1):402-14. Understanding the evidence on use of baby ASA prior to 16 weeks gestation in women at risk of IUGR.

69. Morse K, Williams A, Gardosi J. Fetal growth screening by fundal height measurement. Best Pract Res Clin Obstet Gynaecol. 2009;23:809-18.

70. Gardosi J, Francis A. Controlled trial of fundal height measurement plotted on customised antenatal growth charts. Br J Obstet Gynaecol. 1999;106:309-17.

71. Chang TC, Robson SC, Boys RJ, Spencer JA. Prediction of the small for gestational age infant: which ultrasonic measurement is best? Obstet Gynecol. 1992;80(6):1030-8.

72. Skovron ML, Berkowitz GS, Lapinski RH, et al. Evaluation of early third-trimester ultrasound screening for intrauterine growth retardation. J Ultrasound Med. 1991;10:153-9.

73. American Institute of Ultrasound in Medicine. AIUM practice guideline for performance of obstetric ultrasound examinations. J Ultrasound Med. 2010;29(1):157-66.

74. • Burd I, Srinivas S, Paré E, et al. Is sonographic estimation of fetal weight influenced by formula selection? J Ultrasound Med. 2009;28(8):1019-24.

75. Benson CB, Doubilet PM. Sonographic prediction of gestational age: accuracy of second- and third-trimester fetal measurements. Am J Roentgenol. 1991;157(6):1275-7.

76. Sarris I, Ioannou C, Chamberlain P, et al. for the International Fetal and Newborn Growth Consortium for the 21st Century (INTERGROWTH-21st). Intra- and interobserver variability in fetal ultrasound measurements. Ultrasound Obstet Gynecol. 2012;39:266-73. 
77. Zalud I, Good S, Carneiro G, et al. Fetal biometry: a comparison between experienced sonographers and automated measurements. J Matern Fetal Neonatal Med. 2009;22(1):4350 .

78. Crane JP, Kopta MM. Prediction of intrauterine growth retardation via ultrasonically measured head/abdominal circumference ratios. Obstet Gynecol. 1979;54:597-601.

79. Hadlock FP, Deter RL, Harrist RB, et al. A date-independent predictor of intrauterine growth retardation: femur length/ abdominal circumference ratio. AJR Am J Roentgenol. 1983;141:979-84.

80. Vintzileos AM, Lodeiro JG, Feinstein SJ, et al. Value of fetal ponderal index in predicting growth retardation. Obstet Gynecol. 1986;67:584-8.

81. Reece EA, Goldstein I, Pilu G, Hobbins JC. Fetal cerebellar growth unaffected by intrauterine growth retardation: a new parameter for prenatal diagnosis. Am J Obstet Gynecol. 1987;157:632-8.

82. Dilmen G, Toppare MF, Turhan NO, et al. Transverse cerebellar diameter and transverse cerebellar diameter/ abdominal circumference index for assessing fetal growth. Fetal Diagn Ther. 1996;11(1):50-6.

83. Figueras F, Gardosi J. Should we customize fetal growth standards. Fetal Diagn Ther. 2009;25:297-303.
84. Gardosi J, et al..: Gestation related optimal weight (GROW) program. 2003. https://www.gestation.net/fetal_growth/download grow.htm accessed 12/25/2012.

85. Gardosi J, Francis A. A customized standard to assess fetal growth in a US population. Am J Obstet Gynecol. 2009;201(1):25.e1-7.

86. Fleischer AC, Goldstein RB, Bruner JP, Worrell JA. Doppler sonography in obstetrics and gynecology. In: Callen PW, editor. Ultrasonography in obstetrics and gynecology. 3rd ed. Philadelphia: WB Saunders; 1994. p. 503-23.

87. Ferrazzi E, Bozzo M, Rigano S, et al. Temporal sequence of abnormal Doppler changes in the peripheral and central circulatory systems of the severely growth-restricted fetus. Ultrasound Obstet Gynecol. 2002;19:140-6.

88. Baschat AA, Gembruch U, Harman CR. The sequence of changes in Doppler and biophysical parameters as severe fetal growth restriction worsens. Ultrasound Obstet Gynecol. 2001;18:571-7.

89. Baschat AA, Gembruch U, Weiner CP, Harman CR. Qualitative venous Doppler waveform analysis improves prediction of critical perinatal outcomes in premature growth-restricted fetuses. Ultrasound Obstet Gynecol. 2003;22(3):240-5.

90. Baschat AA, Güclü S, Kush ML, et al. Venous Doppler in the prediction of acid base status of growth restricted fetuses with elevated placental blood flow waveform. Am J Obstet Gynecol. 2004;191(1):277-84. 